\title{
Evaluation of anterior cruciate ligament repair using magnetic resonance imaging
}

\author{
Hanaa Ahmed Kamel' and Hoda Salah Darwish ${ }^{2 *}$ \\ *Correspondence: darwish.hoda@yahoo.com

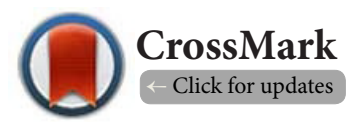 \\ 'Lecturer of Radio-diagnosis, Faculty of Medicine, Tanta University, Egypt. \\ ${ }^{2}$ Lecturer of Radio-diagnosis, Faculty of Medicine, Suez Canal University, Ismailia, Egypt.
}

\begin{abstract}
Purpose: The purpose of this study was to review the MR imaging findings after anterior cruicate ligament (ACL) reconstruction and to study the value of MRI in assessment of ACL reconstrction using arthroscopy as a gold standnad.

Material and methods: Two radiologists reviewed MRI findings of 32 patients post ACL reconstrction retrospectively. Evaluation of MRI findings includes, primary \& sceondary sings of graft failure and ACL graft reconstrcyin complications. Arthroscopy study was performed within 15-20 days from MR examination. Our results of MRI were comapred to the result of arthroscopy. The kappa values for interobserver variability were calculated.
\end{abstract}

Results: A total of 32 male patients were studied, with a mean age of 27 years, Arthroscopy revealed 13 patients with full-thickness ACL graft tears, 8 partial-thickness ACL graft tears and 11 intact ACL grafts. Graft fiber continuty and 100\% graft thickness were most valuableprimary sign in diagnosis of intact graft Complete discontinuous graft was valuable in diagnosis of full-thickness tear. Focal graft thinning was valuable in diagnosis of partial graft tear. Anterior tibial translation and uncovered posterior horn lateral meniscus are secondary sings that helped in differentiating partial or full thickness from intact graft.

Conclusion: We conclude that MRI imaging is a reliable tool for the assessment of ACL reconstruction outcome.

Keywords: Anterior cruciate ligament reconstruction, ACL graft complications, graft impingement, graft tear

\section{Introduction}

Anterior cruciate ligament $(\mathrm{ACL})$ reconstruction is one of the most commonly performed sports medicine procedures in the United States, with approximately 100,000 procedures performed each year [1]. It is the most commonly reconstructed ligament in the knee. Its clinical evaluation of $A C L$ reconstructions is difficult, and MR imaging plays an important role in evaluating the integrity of the $A C L$ graft, as well as in diagnosing complications associated with $A C L$ reconstruction [2].

Most patients who have undergone primary $A C L$ reconstruction report good to excellent outcomes with regard to stability and return to pre-injury activity level [3-5]. However, poor outcomes after primary $\mathrm{ACL}$ reconstruction can generally be classified into one or more of the following categories; Loss of motion, persistent pain, postoperative complications, extensor mechanism dysfunction and recurrent instability [3-6].

Recurrent instability after primary ACL reconstruction has an incidence of $3 \%$ to $10 \%[4,7,8]$. One of the most common etiologies of recurrent instability is graft failure $[9,10]$.

Although it can be difficult to isolate one distinct mechanism of graft failure, three different categories have been described: failure of incorporation, suboptimal surgical technique and traumatic re-injury [11].

The indications for evaluating $A C L$ reconstructions with $M R$ imaging include (a) failure of $A C L$ reconstruction to stabilize the knee, (b) postoperative re-injury to the knee, (c) postoperative stiffness especially extension loss (flexion contracture) and (d) preparation for revision of a failed $A C L$ reconstruction, all of which aid the surgeon in preoperative planning $[12,13]$.

The purpose of this study was to study the diagnostic value of $M R$ imaging in assessment of $A C L$ repair comparing the results with arthroscopy of the knee as a gold standard.

\section{Material and methods}

A total number of 32 patients were included in the study that conducted from January 2012 to February 2014. The MRI images 
Kamel et al. Medical Imaging and Radiology 2014,

http://www.hoajonline.com/journals/pdf/2054-1945-2-6.pdf

doi: 10.7243/2054-1945-2-6

of these patients were evaluated on workstation (VEPRO, Germany).

A random retrospective review of the MR images of the 32 patients was completed by two different radiologists who were unaware of the arthroscopic results. All MR imaging sequences and planes for each case were available for radiologists.

Human ethics committee approval for this study was obtained from hospital institutional review board (IRB).

MRI images were assessed primary sings of graft tear includes; diffuse increased ACL graft signal intensity, location of focal increased graft signal if present (proximal, middle, or distal), graft orientation on sagittal images (either taut between femur and tibia or horizontal or lax), complete $\mathrm{ACL}$ graft discontinuity, the presence of any ACL graft fiber continuity, and focal graft thinning $(100 \%, 50-99 \%$, or $<50 \%$ thickness).

Secondary signs of ACL graft tear include the following; anterior tibial translation in which the posterior cortex of mid lateral tibia translated $>5 \mathrm{~mm}$ anterior to the posterior cortex of the femur on sagittal images, uncovered posterior horn of lateral meniscus (line drawn superior from posterior cortex of lateral tibia intersects the posterior horn of lateral meniscus on sagittal images) posterior cruciate ligament (PCL) hyperbuckling (posterior concavity of PCL on sagittal images), and abnormal posterior PCL line (line tangential to posterior margin of distal $\mathrm{PCL}$ does not intersect femur in distal $5 \mathrm{~cm}$ on sagittal images).

\section{The indications of post operative MRI examination include Post operative instability \\ - Evaluation for meniscus tear, chondral, bone and other ligament injuries. IN PRESS. \\ - Recurrent knee pain with or without recent trauma. \\ - Loss of full extension of their knees or developing knee instability.}

\section{MRI imaging}

All patients underwent MRI knee using MRI scanner (Optima ${ }^{\text {TM }}$ MR 450 W 1.5 Tesla).

MR imaging protocols included the following; T1-weighted spin- echo images in sagittal, coronal and axial planes with TR/TE 500-600/18-20 ms, Proton densityweighted fast spinecho images with fat saturation in sagittal and coronal planes with TR/TE 1000-4500/12-17 ms. T2-weighted fast spin-echo images in sagittal planes with TR/TE 2000-4500/100-120 ms. Gradient-echo images in axial planes with flip angle 30_and TR/TE 30/15.

The echo train length for fast spin-echo images was eight. The number of excitations was one to two. The slice thickness and slice gap for each imaging plane were 3-or 4-mm thick and 1-mm gap for the sagittal plane (except for gradient echo, $1.5-\mathrm{mm}$ thick and $0-\mathrm{mm}$ gap), 4-mm thick and 1 -or $0.5-\mathrm{mm}$ gap for the coronal plane, and 10-mm thick and 2-mm gap for the axial plane.

Sagittal MR imaging was performed with the knee in 0-10_of external rotation to obtain images sagittal to the plane of the ACL.

\section{Femoral and tibial tunnel anatomy \\ Femoral tunnel}

The positioning of the femoral tunnel is the primary factor in maintaining graft isometry and it must be assessed in both the sagittal and coronal planes. In the sagittal plane the tunnel assessed by drawing a line along the posterior cortex of the femur and another line along the roof of the intercondylar notch. The inferior portion of the tunnel should be located at the intersection of these two lines [13-15].

While in the coronal MR image, the intraarticular portion of the femoral tunnel should open at the superolateral posterior margin of the intercondylar notch. If a clock face is superimposed on an coronal MR image with the center at the intercondylar notch, the tunnel should be oriented between 10-and 11-o'clock on the right knee or between 1 -and 2-o'clock on the left knee $[14,15]$.

\section{Tibial tunnel}

The tibial tunnel sagittal images should be oriented parallel to the Blumensaat line which is a line drawn on conventional radiographs along the intercondylar roof (Figures 1A and 1B).

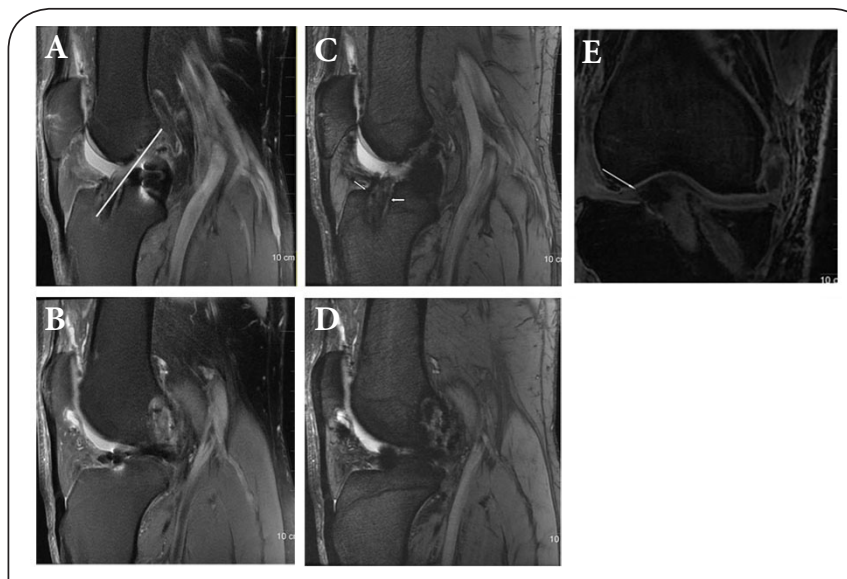

Figure 1. ACL graft impingement in 40 years old man who presented with limited range of motion.

On Sagittal proton density spin echo fat saturation images (A, B) the tibial bone tunnel, is anterior to the intersection of the slope of the intercondylar roof and the proximal tibia (Blumensaat line). On sagittal T2* $\operatorname{MERGE}(\mathbf{C}, \mathbf{D})$, intact graft in the intercondylar notch (2 arrows) with abnormal intermediate signal intensity is seen in the distal portion of the graft. On coronal 3D Fast spin gradient echo Fat saturation (E), the intercondylar notch is show overgrown and impinges on the graft, with fibrous tissue (arrow), due to impingement encases it anteriorly \& extends into tunnel.

The distal portion of the tunnel should start near the tibial tuberosity, and the intraarticular opening of the tunnel should be completely posterior to Blumensaat line [14-16]. 


\section{Normal graft MRI features}

1) Low signal intensity on short-TE sequences.

2) Intermediate signal within grafts from approximately 4 to 8 months after reconstruction.

3) Complete resolving by 12 months.

The increased signal is thought to be due to graft revascularization and synovialization [18] (Figures 1C and 1D).

\section{ACL reconstruction complications}

The main complications divided into two groups on the basis of clinical symptoms: decreased range of motion and laxity.

\section{Complications leading to decreased range of motion Impingement}

If the tibial tunnel is positioned too far anteriorly (i.e., partially or completely anterior to the intersection of the Blumensaat line, or to its MR equivalent, with the tibia), the graft can become impinged on by the roof of the intercondylar notch $[14,16,19]$ (Figure 1E).

\section{Radiography}

MRI will show a malpositioned tibial tunnel (Figures 2A and 2B) and it may show increased signal in the graft on T1-and T2weighted sequences in the setting of notch impingement [15] (Figures 2C and 2D).

\section{Arthrofibrosis}

On MRI, both forms are low signal intensity on $\mathrm{T} 1$-weighted sequences and are predominantly low signal on T2-weighted sequences $[15,17]$. It may be focal or diffuse, the focal form is a more common complication of $\mathrm{ACL}$ reconstruction and is seen as a nodule of low signal just anterior to (cyclops lesion) the distal end of the graft between the femur and tibia.

The diffuse form seen as an ill-defined spiculated area of low signal within the Hoffa fat pad or a mass like area of decreased signal anterior and posterior to the graft and can extend to the joint capsule with possible synovial hypertrophy and capsular thickening $[13,15]$.

\section{Cystic degeneration (ganglion cyst formation)}

A late complication and usually occurs in the tibial tunnel within the graft and follows fluid signal on all MR pulse sequences [15].

\section{Intraarticular bodies}

Composed of articular cartilage, cortical bone, or cancellous bone will be intermediate to low on T2-weighted sequences [20].

\section{Complications leading to laxity Graft tear}

Grafts are most susceptible to injury during the remodeling process, which occurs approximately 4-8 months after surgery [15]. Primary signs include graft signal abnormalities including;
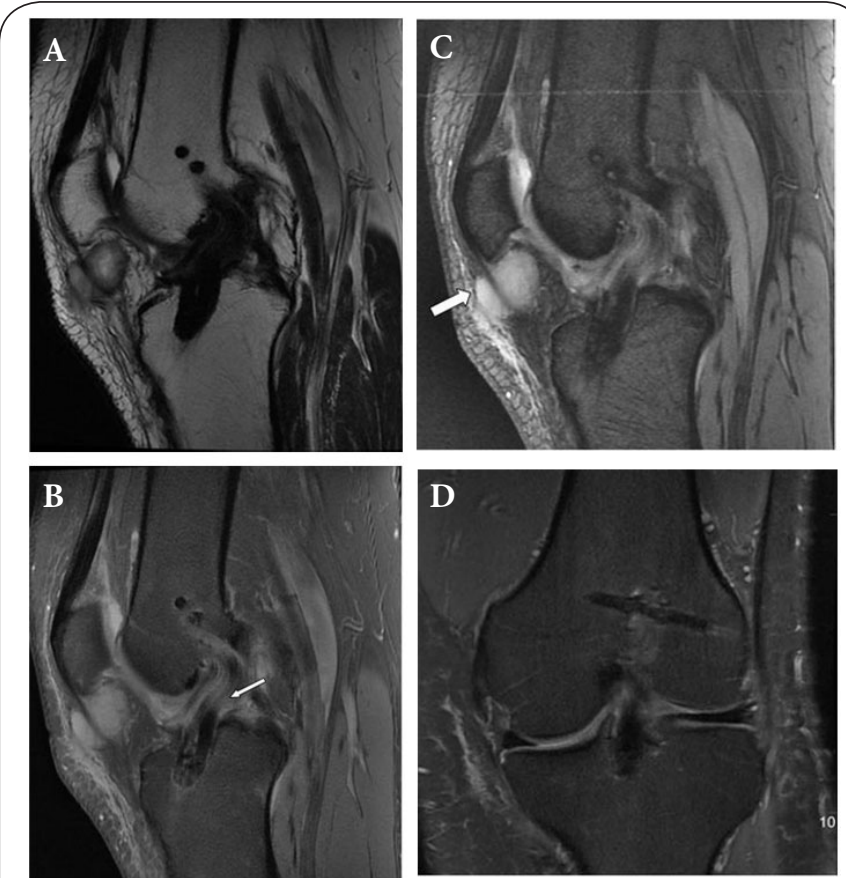

Figure 2. 34 year-old-male with knee pain 6 months after anterior cruciate ligament reconstruction.

Sagittal T2 (A), show normally positioned ACL graft and tibial tunnel opening, with the entire tunnel opening is positioned posterior to the intersection of MRI equivalent of Blumnensaat line and tibia. On Sagittal Proton Density Fat saturation (B), intermediate signal intensity within the graft substance secondary to graft revascularization seen. Associated superficial infrapatellar bursitis with oval shaped high signal intensity fluid seen surrounding the inferior patellae tendon as well as between the skin and inferior patellar tendon is shown on Sagittal T2* MERGE (C). On coronal proton density Fat saturation (D), normally positioned femoral tunnel seen between 10 and 11 o'clock position.

increased signal on T2-weighted sequences (Figures 3A and 3B), graft thickness, and fiber discontinuity. Secondary signs include anterior tibial translation and an uncovered posterior horn of the lateral meniscus [21,22].

\section{Graft stretching}

This term used to describe intact graft fibers in the clinical setting of increased laxity. MRI findings may include posterior bowing of the graft seen in the sagittal plane (Figure $3 \mathrm{C}$ ). If the femoral tunnel is placed too far anteriorly, then the graft is subject to increased strain when the knee is flexed, which can lead to graft tightening or stretching $[15,23,24]$.

\section{Miscellaneous lesions}

Include complications of the fixation devices, harvest site complications, septic arthritis, and vascular complications [20].

\section{Statistical analysis}

Data was evaluated by using statistical package for social sciences (SPSS) software version 17. 

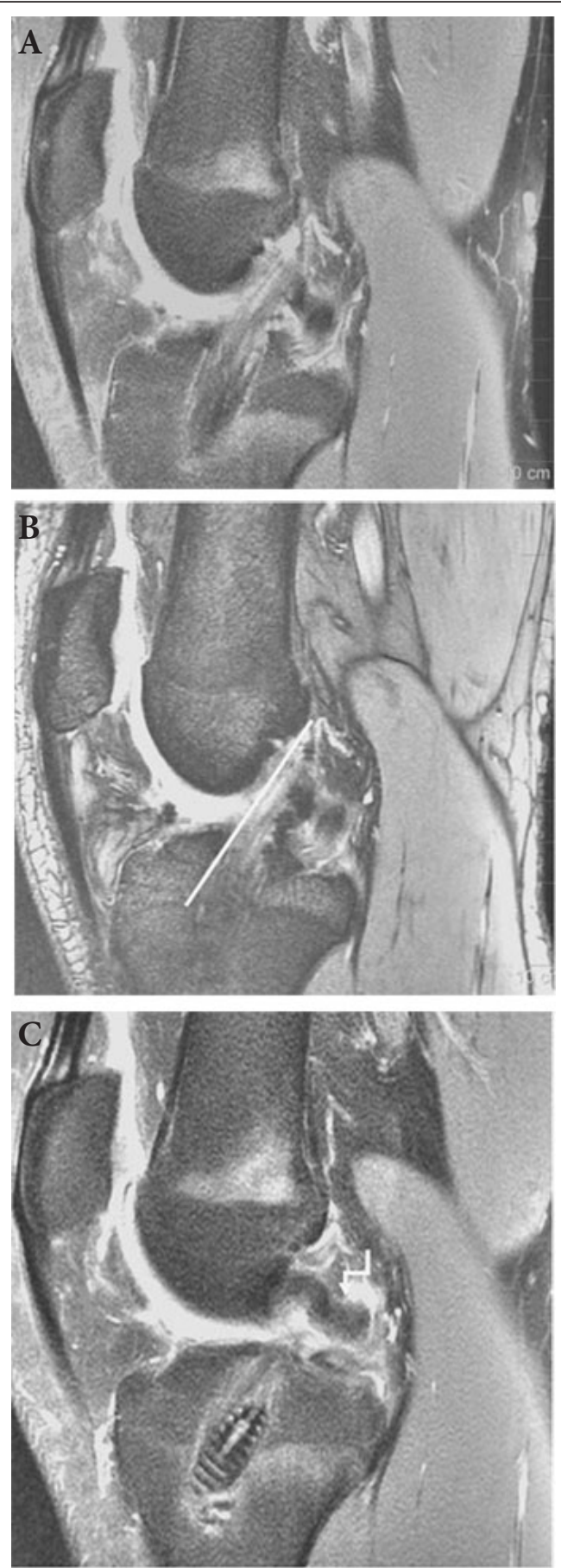

Figure 3. 18-years-old male patient who had undergone ACL reconstruction 11 months earlier, presented with knee pain with normal range of knee extension.

Sagittal Proton Density Fat saturation \& Sagittal T2* Merge (A, B), show continuous ACL graft with areas of high signal intensity within it (double arrows), which indicate partial thickness tear of the graft. Note, orientation of the graft approximately parallel to intercondylar roof. On Sagittal PD Fat Sat (C), hyperbuckling of the posterior cruciate ligament seen (arrow).
Retrospective MR imaging results were compared with the arthroscopic results to determine sensitivity, specificity, positive predictive value, negative predictive value, and accuracy of the MRI in assessment ACL graft.

Kappa values for interobserver variability were calculated $(0.21-0.40=$ fair agreement, $0.41-0.60=$ moderate agreement, $0.61-0.80=$ substantial agreement, $0.81-1.0=$ almost perfect agreement).

\section{Results \\ Patient data}

32 Patients were included in this study all patients were males. Youngest patient included in our study was 18 years of age and oldest 54 years of age with the mean age of 27 years.

The average time interval from initial ACL reconstruction surgery to MR imaging examination was less was less than 1 year duration in 13 patients $(40.6 \%)$ and more than 1 year graft duration in 19 patients (59.4\%). Arthroscopy study performed within 15-20 days from MR examination.

\section{Post operative MRI findings}

The MR imaging of the cases revealed; primary and secondary signs of ACL graft failure A-The primary signs.

- Diffuse increased signal in the region of the ACL graft on the proton density-weighted images was found in $45 \%$ of the full-thickness tears, $55 \%$ of partial-thickness tears, and $10 \%$ of intact grafts.

- In our study we also found that, the diagnosis of fullthickness graft tear versus partial-thickness tear or intact graft resulted in $50 \%$ sensitivity, $70 \%$ specificity, $22 \%$ positive predictive value, $85 \%$ negative predictive value, and $65 \%$ accuracy.

- The diagnosis of partial-thickness ACL graft versus fullthickness tear or intact graft resulted in a $43 \%$ sensitivity, $72 \%$ specificity, $72 \%$ positive predictive value, $60 \%$ negative predictive value, and $59 \%$ accuracy.

- The diagnosis of partial or fullthickness ACL graft tear versus intact graft resulted in a $43 \%$ sensitivity, $90 \%$ specificity, $92 \%$ positive predictive value, $46 \%$ negative predictive value, and $59 \%$ accuracy.

- The kappa value was 0.40 (moderate agreement) for diffuse increased graft signal.

- Focal increased signal in the ACL graft on proton densityweighted images was detected with $75 \%$ of full-thickness graft tears (distal in $25 \%$, middle in $12 \%$, middle and distal in $12 \%$, and proximal in $25 \%$ ), $28 \%$ of partial-thickness tears, and $40 \%$ of intact grafts.

- The diagnosis of full-thickness graft tear versus partialthickness tear or intact graft resulted in $75 \%$ sensitivity, $67 \%$ specificity, $41 \%$ positive predictive value, $90 \%$ negative predictive value, and $68 \%$ accuracy.

- The diagnosis of partial-thickness ACL graft versus fullthickness tear or intact graft resulted in $28 \%$ sensitivity, $44 \%$ specificity, $29 \%$ positive predictive value, $43 \%$ 
negative predictive value, and 39\% accuracy.

- The diagnosis of partial or full thickness ACL graft tear versus intact graft resulted in $45 \%$ sensitivity, $60 \%$ specificity, $71 \%$ positive predictive value, $33 \%$ negative predictive value, and $50 \%$ accuracy.

- The kappa value was 0.75 (substantial agreement) for focal increased graft signal.

- ACL graft orientation: The orientation of the ACL graft on sagittal images was found to be lax or horizontal in $12.5 \%$ of full-thickness graft tears, $43 \%$ of partial-thickness tears, and $10 \%$ of intact grafts. The diagnosis of full-thickness graft tear versus partial-thickness tear or intact graft resulted in a 13\% sensitivity, $71 \%$ specificity, 13\% positive predictive value, $71 \%$ negative predictive value, and $56 \%$ accuracy.

- The diagnosis of partial-thickness ACL graft versus full thickness or intact graft resulted in the following $43 \%$ sensitivity, $89 \%$ specificity, $75 \%$ positive predictive value, $67 \%$ negative predictive value, and $69 \%$ accuracy.

- The diagnosis of partial or full thickness ACL graft versus intact graft resulted in a $31 \%$ sensitivity, $90 \%$ specificity, $88 \%$ positive predictive value, $38 \%$ negative predictive value, and $50 \%$ accuracy.

- The kappa value was 0.31 (fair agreement) for lax or horizontal ACL graft orientation.

\section{ACL graft discontinuity}

- In the sagittal plane, complete graft discontinuity (Figures 4A and $4 \mathrm{~B}$ ) was seen in $50 \%$ of full-thickness tears, $14 \%$ of partial-thickness tears, and $10 \%$ of intact grafts. In the coronal plane, complete graft discontinuity was seen in $75 \%$ of full-thickness tears, $14 \%$ of partial-thickness tears, and $0 \%$ of intact grafts.

- However, when we use sagittal and coronal planes, complete graft discontinuity was seen in $50 \%$ of full thickness graft tears and seen in $0 \%$ of partial-thickness tears and intact grafts. Using the coronal plane, the diagnosis of full-thickness graft tear versus partial-thickness tear or intact graft resulted in a 75\% sensitivity, 91\% specificity, $75 \%$ positive predictive value, $91 \%$ negative predictive value, and $87 \%$ accuracy.

- Using the coronal and sagittal planes, the sensitivity was $50 \%$; specificity, $100 \%$; positive predictive value, $100 \%$; negative predictive value, $86 \%$; and accuracy, $87 \%$.

- When we use coronal plane in the diagnosis of partialthickness ACL graft versus full-thickness tear or intact graft, the sensitivity was 14\%; specificity, $67 \%$; positive predictive value, 25\%; negative predictive value, 50\%; and accuracy, $44 \%$. Using the coronal and sagittal planes, the sensitivity was $0 \%$; specificity was $78 \%$; positive predictive value was 0\%; negative predictive value, 50\%; and accuracy, $44 \%$. - Using the coronal plane in the diagnosis of ACL graft tear either partial or full thickness versus intact graft, the sensitivity in our study was $36 \%$; specificity, $100 \%$; positive
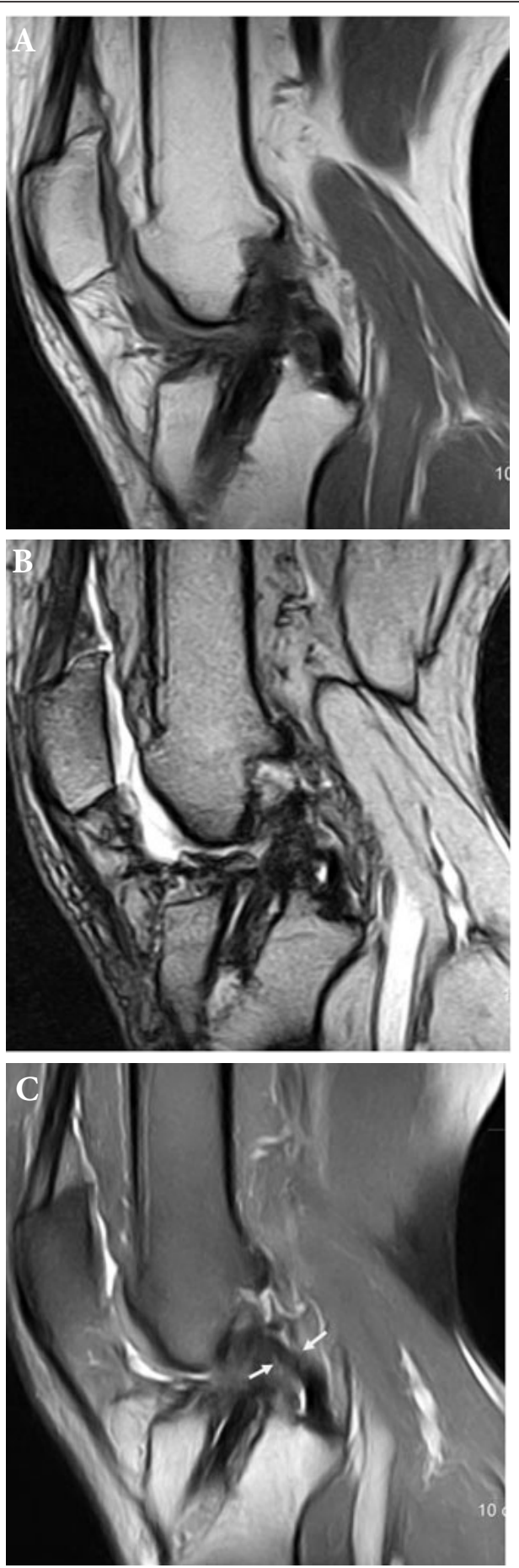

Figure 4. 44-years-old man who had undergone anterior cruciate ligament reconstruction 5 years ago, presented with clinical signs of complete graft failure and instability.

Sagittal T1 WI (A), shows complete discontinuity of fibres of ACL graft (arrow). Sagittal gradient image (B), shows complete disconituity of the graft, whick is replaced with fliud signal. On Sagittal T1 3D image (C), complete disruption of ACF graft fibres and buckling of posterior cruciate ligament well seen (double arrows). 
Kamel et al. Medical Imaging and Radiology 2014,

predictive value, $100 \%$; negative predictive value, $42 \%$; and the accuracy was $50 \%$.

- However, using coronal and sagittal planes, the sensitivity was $18 \%$; specificity, $100 \%$; positive predictive value, $100 \%$; negative predictive value, $36 \%$; and accuracy, $44 \%$.

- The kappa value was 0.11 (poor agreement) for complete graft fiber discontinuity in the sagittal plane and 1.00 (almost perfect agreement) for the coronal plane.

\section{ACL graft fiber continuity}

In the current study, MRI were evaluated for ACL graft fiber continuity in both sagittal and coronal planes. Our results revealed that coronal plane is outperformed the sagittal plane; the accuracy in diagnosing intact graft or partial-thickness tear was $78 \%$ for the sagittal plane and $88 \%$ for the coronal plane. In our study, the diagnosis of intact graft or partial-thickness tear versus full-thickness tear resulted in a $92 \%$ sensitivity, $75 \%$ specificity, $92 \%$ positive predictive value, $75 \%$ negative predictive value, and $88 \%$ accuracy.

- The diagnosis of intact $A C L$ graft versus full-thickness

or partial-thickness tear resulted in a $100 \%$ sensitivity, $36 \%$ specificity, $42 \%$ positive predictive value, $100 \%$ negative predictive value, and $56 \%$ accuracy.

The kappa value was 1.00 (almost perfect agreement) for graft fiber continuity in the coronal plane.

\section{Graft thickness}

A 100\% graft thickness (no thinning) on coronal MR images in the diagnosis of intact graft versus partial- or full-thickness tear resulted in a $60 \%$ sensitivity, $73 \%$ specificity, $48 \%$ positive predictive value, $81 \%$ negative predictive value, and resulted in $68 \%$ accuracy.

A 100\% graft thickness (no thinning) on MR images in the diagnosis of intact graft or partial-thickness tear versus fullthickness tear revealed;

- Using the sagittal plane, sensitivity was $41 \%$; specificity, $100 \%$; positive predictive value, $100 \%$; negative predictive value, $35 \%$; and accuracy, $56 \%$. And in using the MRI coronal plane, the sensitivity was $50 \%$; specificity, $100 \%$; positive predictive value, $100 \%$; negative predictive value, $40 \%$; and accuracy $62 \%$.

- The kappa value was 0.58 (moderate agreement) for graft thinning in the sagittal plane and 0.74 (substantial agreement) for graft thinning in the coronal plane.

$B-M R$ imaging of the secondary signs of $A C L$ reconstruction failure as follows;

1. Anterior tibial translation; on sagittal images it was present in $25 \%$ of the full-thickness graft tears, $57 \%$ of partialthickness tears, and found in $10 \%$ of intact grafts.

2. PCL hyperbuckling; Hyperbuckling of the PCL (Figures $3 \mathrm{C}$ and $4 \mathrm{C}$ ) on mid sagittal images was found in $37.5 \%$ of the full-thickness graft tears, $43 \%$ of partial-thickness tears, and found in $30 \%$ of intact grafts.

3. Uncovered posterior horn of the lateral meniscus; on sagittal images was present in $12.5 \%$ of the full-thickness graft tears, $29 \%$ of partia-thickness tears, and not seen in intact grafts.

4. Abnormal PCL line; on mid sagittal images it was present in $25 \%$ of the full-thickness graft tears, $50 \%$ of partial thickness tears, and in $30 \%$ of intact grafts.

\section{Graft complication}

- Regarding arthrofibrosis, cyclops lesions diagnosed by

MRI in 8 cases, and diffuse arthrofibrosis seen in 12 cases which confirmed by arthroscopy and pathology.

- 14/32 patients showing ACL graft impingement (43.7\%), seven of them caused by abnormal anterior placement of the tibial tunnel, 3 cases caused by abutting the ACL graft to the roof of intercondylar notch and four cases by notch osteophyte.

- Tunnel cystic degeneration of the femoral tunnel in 5 cases and the tibial tunnel in 4 cases.

- Four cases with loose body in the anterior knee are diagnosed.

- Meniscal tear seen in 3 cases.

- Harvest site complication seen in 4 cases as patellar fractures.

\section{Discussion}

The most commonly reconstructed ligament in the knee is the ACL. Its clinical evaluation can be difficult. Post operative $\mathrm{ACL}$ graft patients complaining of knee instability and loss of extension or pain are indicated for clinical and radiological examination aiming to diagnose $A C L$ graft failure, $A C L$ graft complication or other internal derangement.

The MR imaging plays an important role in the assessment of ACL graft and diagnosing complications associated with $A C L$ reconstruction.

Retrospective analysis of the primary MR imaging signs of $A C L$ graft tear evaluated in this study revealed that evaluation for graft fiber continuity, complete graft discontinuity, and graft thickness are most valuable of of graft failure and poor outcome.

Our results also showing that identification of continuous graft fibers in the coronal plane can discriminate between intact graft and graft tear either partial or full thickness, as well as between intact or partial-thickness graft tear and full-thickness tear.

ACL graft discontinuity, focal thinning and presence of any intact $A C L$ graft fibers were better assessed in the coronal plane than in the sagittal plane. We noticed that complete discontinuous graft on both sagittal and coronal planes increased specificity and negative predictive value to $100 \%$ in the diagnosis of a full thickness graft tear.

In our study, the other primary signs of graft tear were less valuable and we found that increased graft signal is insensitive in diagnosing graft tear, also we found that lax graft fiber orientation is not helpfull in diagnosing a tear with sensitivity of $31 \%$. 
Kamel et al. Medical Imaging and Radiology 2014,

Retrospective analysis of the secondary signs of $A C L$ graft tear with MR imaging in our study, revealed that anterior tibial translation and uncovered posterior horn of lateral meniscus were more valuable than other secondary signs in discriminating full thickness $\mathrm{ACL}$ graft tear from intact graft. However, they had low sensitivity (45\%).

While, the other secondary signs were of little values in diagnosis of ACL graft tear having low sensitivity and specificity.

Some auothers reported that increased signal intensity of clinically stable $A C L$ grafts increases up to 12 months after $A C L$ reconstruction surgery and then decreases over the subsequent 12 months $[\mathbf{2 5 , 2 6 ]}$. This increase of single has been attributed to revascularization and cellular infiltration [27] and also has been considered an indeterminate finding in the assessment of ACL graft integrity [28].

In our study 4 patients with intact graft confirmed at arthroscopy, one of them had diffuse increased signal and two of them had focal increased signal. The patient who had diffuse increased signal had a time interval of 44 months from $A C L$ graft placement to MR imaging, and the other three patients had an average time interval of 26 months.

A longer time interval from $A C L$ graft surgery to $M R$ imaging (36-month average compared with 25-month average for the remaining intact $A C L$ grafts) was noted in 2 patients with focal increased signals.

Our results also revealed relative insensitivity in the detection of a partial-thickness ACL graft tear on MR imaging.

\section{Conclusion}

From our study we conclusde that MR imaging is a reliable diagnostic tool for evaluation of $\mathrm{ACL}$ graft reconstruction poor outcomes including ACL graft failure and complications. Also we conclusde that complete $\mathrm{ACL}$ graft discontinuitywas the most valuable primary sign in the diagnosis of full thickness tear and can discriminat full thickness tear from partial thickness tear and intact graft.

\section{List of abbreviations}

MRI: Magnetic resonance imaging

$\mathrm{ACL}$ : Anterior cruciate ligament

IRB: Institutional review board

Competing interests

The authors declare that they have no competing interests.

Authors' contributions

\begin{tabular}{|l|c|c|}
\hline Authors' contributions & HAK & HSD \\
\hline Research concept and design & $\checkmark$ & $\checkmark$ \\
\hline Collection and/or assembly of data & $\checkmark$ & $\checkmark$ \\
\hline Data analysis and interpretation & $\checkmark$ & $\checkmark$ \\
\hline Writing the article & -- & $\checkmark$ \\
\hline Critical revision of the article & -- & $\checkmark$ \\
\hline Final approval of article & $\checkmark$ & $\checkmark$ \\
\hline Statistical analysis & -- & $\checkmark$ \\
\hline
\end{tabular}

Acknowledgement

The authors would like to thank their colleagues for the support and patients for their trust.

Publication history

Senior Editor: Domenico Rubello, Santa Maria della Misericordia Hospital, Italy.

Received: 16-Oct-2014 Final Revised: 22-Nov-2014

Accepted: 22-Dec-2014 Published: 27-Dec-2014

\section{References}

1. Csintalan RP, Inacio MC and Funahashi TT. Incidence rate of anterior cruciate ligament reconstructions. Perm J. 2008; 12:17-21. | PubMed Abstract | PubMed Full Text

2. Recht MP and Kramer J. MR imaging of the postoperative knee: a pictorial essay. Radiographics. 2002; 22:765-74. | Article | PubMed

3. Harner CD, Giffin JR, Dunteman RC, Annunziata CC and Friedman MJ. Evaluation and treatment of recurrent instability after anterior cruciate ligament reconstruction. J Bone Joint Surg. 2000; 82A:1652-1664.

4. Bach BR, Jr., Tradonsky S, Bojchuk J, Levy ME, Bush-Joseph CA and Khan $\mathrm{NH}$. Arthroscopically assisted anterior cruciate ligament reconstruction using patellar tendon autograft. Five- to nine-year follow-up evaluation. Am J Sports Med. 1998; 26:20-9. | Article | PubMed

5. Freedman KB, D'Amato MJ, Nedeff DD, Kaz A and Bach BR, Jr. Arthroscopic anterior cruciate ligament reconstruction: a metaanalysis comparing patellar tendon and hamstring tendon autografts. Am J Sports Med. 2003; 31:2-11. | Article | PubMed

6. Kamath GV, Redfern JC, Greis PE and Burks RT. Revision anterior cruciate ligament reconstruction. Am J Sports Med. 2011; 39:199-217. | Article | PubMed

7. Noyes FR and Barber-Westin SD. A comparison of results in acute and chronic anterior cruciate ligament ruptures of arthroscopically assisted autogenous patellar tendon reconstruction. Am J Sports Med. 1997; 25:460-71. | Article | PubMed

8. Bach BR, Jr. Revision anterior cruciate ligament surgery. Arthroscopy. 2003; 19 Suppl 1:14-29. | Article | PubMed

9. Harter RA, Osternig LR, Singer KM, James SL, Larson RL and Jones DC. Long-term evaluation of knee stability and function following surgical reconstruction for anterior cruciate ligament insufficiency. Am J Sports Med. 1988; 16:434-43. | Article | PubMed

10. Howe JG, Johnson RJ, Kaplan MJ, Fleming B and Jarvinen M. Anterior cruciate ligament reconstruction using quadriceps patellar tendon graft. Part I. Long-term followup. Am J Sports Med. 1991; 19:447-57. | Article I PubMed

11. S.P. Morozov, E.S. Belysheva, V.E. Synitsyn and A.V. Korolev Moscow/ $\mathrm{RU}$. Magnetic resonance imaging of anterior cruciate ligament (ACL) autografting. ECR. 2006.

12. Lind $M$, Menhert $F$ and Pedersen $A B$. The first results from the Danish $A C L$ reconstruction registry: epidemiologic and 2 year follow-up results from 5,818 knee ligament reconstructions. Knee Surg Sports Traumatol Arthrosc. 2009; 17:117-24. | Article | PubMed

13. Papakonstantinou O, Chung CB, Chanchairujira K and Resnick DL. Complications of anterior cruciate ligament reconstruction: MR imaging. Eur Radiol. 2003; 13:1106-17. | PubMed

14. Tomczak RJ, Hehl G, Mergo PJ, Merkle E, Rieber A and Brambs HJ. Tunnel placement in anterior cruciate ligament reconstruction: MRI analysis as an important factor in the radiological report. Skeletal Radiol. 1997; 26:409-13. | Article | PubMed

15. Sanders TG. MR imaging of postoperative ligaments of the knee. Semin Musculoskelet Radiol. 2002; 6:19-33. | Article | PubMed

16. Howell SM and Clark JA. Tibial tunnel placement in anterior cruciate ligament reconstructions and graft impingement. Clin Orthop Relat Res. 1992; 187-95. | Article | PubMed

17. Recht MP, Parker RD and Irizarry JM. Second time around: evaluating the postoperative anterior cruciate ligament. Magn Reson Imaging Clin N Am. 2000; 8:285-97. | PubMed

18. Roberts CC, Towers JD, Spangehl MJ, Carrino JA and Morrison WB. 
Kamel et al. Medical Imaging and Radiology 2014,

http://www.hoajonline.com/journals/pdf/2054-1945-2-6.pdf

Advanced MR imaging of the cruciate ligaments. Radiol Clin North Am. 2007; 45:1003-16. | Article | PubMed

19. Manaster BJ, Remley K, Newman AP and Mann FA. Knee ligament reconstruction: plain film analysis. AJR Am J Roentgenol. 1988; 150:33742. | Article | PubMed

20. Meyers AB, Haims AH, Menn $K$ and Moukaddam H. Imaging of anterior cruciate ligament repair and its complications. AJR Am J Roentgenol. 2010; 194:476-84. | Article | PubMed

21. Horton LK, Jacobson JA, Lin J and Hayes CW. MR imaging of anterior cruciate ligament reconstruction graft. AJR Am J Roentgenol. 2000; 175:1091-7. | Article | PubMed

22. Milano G, Mulas PD, Ziranu F, Piras S, Manunta A and Fabbriciani C. Comparison between different femoral fixation devices for $A C L$ reconstruction with doubled hamstring tendon graft: a biomechanical analysis. Arthroscopy. 2006; 22:660-8. | Article | PubMed

23. Fu FH, Bennett CH, Ma CB, Menetrey J and Lattermann C. Current trends in anterior cruciate ligament reconstruction. Part II. Operative procedures and clinical correlations. Am J Sports Med. 2000; 28:124-30. | Article | PubMed

24. White LM, Kramer J and Recht MP. MR imaging evaluation of the postoperative knee: ligaments, menisci, and articular cartilage. Skeletal Radiol. 2005; 34:431-52. | Article | PubMed

25. Murakami Y, Sumen Y, Ochi M, Fujimoto E, Adachi N and Ikuta Y. MR evaluation of human anterior cruciate ligament autograft on oblique axial imaging. J Comput Assist Tomogr. 1998; 22:270-5. | Article | PubMed

26. Stockle U, Hoffmann R, Schwedke J, Lubrich J, Vogl T, Sudkamp NP and Haas N. Anterior cruciate ligament reconstruction: the diagnostic value of MRI. Int Orthop. 1998; 22:288-92. | PubMed Abstract | PubMed Full $\underline{\text { Text }}$

27. Yamato $M$ and Yamagishi T. MRI of patellar tendon anterior cruciate ligament autografts. J Comput Assist Tomogr. 1992; 16:604-7. | Article | PubMed

28. Cheung Y, Magee TH, Rosenberg ZS and Rose DJ. MRI of anterior cruciate ligament reconstruction. J Comput Assist Tomogr. 1992; 16:134-7.

PubMed

\section{Citation:}

Kamel HA and Darwish HS. Evaluation of anterior cruciate ligament repair using magnetic resonance imaging. Med Imaging Radiol. 2014; 2:6.

http://dx.doi.org/10.7243/2054-1945-2-6 